\title{
Phase I and Pharmacokinetic Study of the Polyamine Synthesis Inhibitor SAM486A in Combination with 5-Fluorouracil/ Leucovorin in Metastatic Colorectal Cancer
}

\author{
Lia van Zuylen, ${ }^{1}$ John Bridgewater, ${ }^{2}$ \\ Alex Sparreboom, ${ }^{1}$ Ferry A.L.M. Eskens, ${ }^{1}$ \\ Peter de Bruijn,, ${ }^{1}$ Ivo Sklenar, ${ }^{3}$ \\ Andre S.T. Planting, ${ }^{1}$ Les Choi, ${ }^{3}$ Douglas Bootle, ${ }^{3}$ \\ Christian Mueller, ${ }^{3}$ Jonathan A. Ledermann, ${ }^{2}$ and \\ Jaap Verweij ${ }^{1}$ \\ ${ }^{1}$ Department of Medical Oncology, Erasmus MC-Daniel den Hoed \\ Cancer Centre, Rotterdam, the Netherlands; ${ }^{2}$ Royal Free and \\ University College Medical School, London, United Kingdom; and \\ ${ }^{3}$ Novartis Pharma AG, Basel, Switzerland
}

\begin{abstract}
Purpose: The purpose of our study was to determine the maximum-tolerated dose, dose-limiting toxicity, safety profile, and pharmacokinetics of the polyamine synthesis inhibitor SAM486A given in combination with 5-fluorouracil/ leucovorin $(5-F U / L V)$ in cancer patients.

Experimental Design: Patients with advanced colorectal cancer were treated with $5-\mathrm{FU}$ [bolus $\left(400 \mathrm{mg} / \mathrm{m}^{2}\right)$ followed by a $22-\mathrm{h}$ infusion $\left.\left(600 \mathrm{mg} / \mathrm{m}^{2}\right)\right]$ and $\mathrm{LV}\left(200 \mathrm{mg} / \mathrm{m}^{2}\right)$ and escalating doses of SAM486A, 1-3-h infusion daily for 3 days. Plasma sampling was performed to characterize the pharmacokinetics and pharmacodynamics of the combination
\end{abstract}

Results: Twenty-seven patients with metastatic colorectal cancer and 1 with pseudomyxoma peritonei were treated. Twenty-six patients received SAM486A in the combination at doses ranging from 25 to $150 \mathrm{mg} / \mathrm{m}^{2} /$ day. Dose-limiting toxicity consisting of fatigue grade 3 was seen at $150 \mathrm{mg} / \mathrm{m}^{2}$ / day. Other adverse events included neutropenia, hand and foot syndrome, nausea, vomiting, diarrhea, and constipation. Fifteen of 26 patients evaluable for best response according to the Southwest Oncology Group criteria achieved a partial response $[8(30 \%)$ of 26$]$ or stable disease [ $9(35 \%)$ of 26]. SAM486A did not influence the pharmacokinetics of 5-FU, and SAM486A clearance was similar to that when used as a single agent.

Conclusions: The novel molecular agent SAM486A is tolerable and safe in combination with a standard 5-FU

Received 8/20/02; revised 11/27/03; accepted 12/10/03.

The costs of publication of this article were defrayed in part by the payment of page charges. This article must therefore be hereby marked advertisement in accordance with 18 U.S.C. Section 1734 solely to indicate this fact.

Requests for reprints: Lia van Zuylen, Department of Medical Oncology, Erasmus MC-Daniel den Hoed Cancer Centre, Groene Hilledijk 301, 3075 EA Rotterdam, the Netherlands. Phone: 31-10-4391906; Fax: 31-10-4391003; E-mail: c.vanzuylen@erasmusmc.nl. regimen in patients with advanced colorectal cancer. The dose of SAM486A recommended for additional studies with this combination is $125 \mathrm{mg} / \mathrm{m}^{2} / \mathrm{day}$. A disease-directed evaluation of SAM486A using this regimen is warranted.

\section{INTRODUCTION}

The polyamines spermidine and spermine play an essential role in the growth of cells, although their specific mechanism of action remains to be elucidated. Tumor cells have an altered polyamine homeostasis resulting in elevated polyamine pools. The key process in the biosynthesis of polyamines is the conversion from putrescine to spermidine and spermine for which $S$-adenosyl methionine decarboxylase (SAMDC) activity is the rate-limiting step (1). The activity of this enzyme can specifically be inhibited by novel agents such as SAM486A (2). In in vitro studies SAM486A depleted spermine and spermidine pools, whereas putrescine pools increased (2). SAM486A showed growth-inhibitory effects on human melanoma-, breast cancer-, and bladder cancer cell lines (3-6) with a similar spectrum of in vivo activity especially in melanoma and prostate cancer xenografts with almost complete inhibition of growth over the treatment period $(3,7)$. Recently, two Phase I studies with SAM486A in patients with various advanced solid tumors using a dosing schedule of either 120-h infusions every 4 weeks or 4 weekly infusions followed by 2 weeks off therapy demonstrated that the primary dose-limiting toxicity (DLT) was myelosuppression $(8,9)$. Nonhematological side effects included gastrointestinal toxicity (nausea/vomiting), fatigue (mild and short lasting), facial paresthesias and flushing, and alopecia. No complete or partial responses were recorded.

For some time, 5-fluorouracil (5-FU) in combination with leucovorin (LV) has been the standard palliative chemotherapy for metastatic colorectal cancer (10). Recently, newer drugs such as oxaliplatin and irinotecan have contributed to improved survival and are being incorporated into novel schedules (1114). In addition to these chemotherapeutic agents, cellular targets have been the basis for novel approaches of which $S$ adenosyl-methionine decarboxylase is one. Adenocarcinoma of the colon contains high levels of $S$-adenosyl methionine decarboxylase (15), and consequent on positive xenograft data, ${ }^{4}$ a combination of 5-FU/LV with SAM486A was considered to be a rational option. We performed a Phase I and pharmacological study with the aim of developing a once-every-2-weekstreatment regimen based on SAM486A combined with a 5-FU/LV regimen (the de Gramont regimen), an effective regimen with less toxicity than the more common once-every-4weeks regimen (16).

\footnotetext{
${ }^{4}$ Novartis, data on file.
} 


\section{PATIENTS AND METHODS}

Eligibility. Patients with a histologically confirmed diagnosis of locally advanced progressive or metastatic colorectal cancer, or patients with solid tumors of any kind for which no standard therapies exist with greater potential benefit than 5-FU/LV and SAM486A, were candidates for this study. Additional eligibility criteria were: age $\geq 18$ years; Karnofsky performance status $\geq 60 \%$; life expectancy of at least 3 months; off previous anticancer therapy for at least 4 weeks; adequate bone marrow function (absolute neutrophil count $\geq 2.0 \times 10^{9} /$ liter; platelet count $\geq 100 \times 10^{9} /$ liter), normal hepatic function (bilirubin level normal; other liver function tests $\leq 2.5$ times upper limit of normal or $\leq 5$ times upper limit of normal in case of the presence of liver metastases) and normal renal function (calculated creatinine clearance $\geq 60 \mathrm{ml} / \mathrm{min}$ ); no severe cardiac insufficiency (New York Heart Association class III and IV); and a baseline left ventricular ejection fraction within normal limits, measured by multiple gated acquisition scan or cardiac ultrasound. Written informed consent was obtained from all patients, and the Institutional Ethics Committees approved the study. Because the SAM486A dose-finding study was combined with a standard treatment for locally advanced progressive or metastatic colorectal cancer, there were no concerns that most of the patients in this Phase I study (20 of 26) had not received previous standard chemotherapy. For the patients with locally advanced progressive disease, there were no local treatment options like surgery.

Pretreatment and Follow-Up Studies. Pretreatment evaluation consisted of recording the medical history, physical examination, laboratory studies, electrocardiography, and assessment of the left ventricular ejection fraction. Computer tomographic scans were performed for tumor measurements. General laboratory studies included a complete blood cell count, differential WBC, electrolytes (sodium, potassium, chloride, calcium, and inorganic phosphate), creatinine, urea, alkaline phosphatase, aspartate aminotransferase, alanine aminotransferase, lactate dehydrogenase, bilirubin, total protein, albumin, glucose, uric acid, and urinalysis. History, physical examination, and toxicity scoring (according to the National Cancer Institute/ NIH Common Toxicity Criteria) were repeated weekly. Complete blood cell counts, including differential WBC, were repeated weekly and, in case of abnormalities, twice weekly; the other laboratory studies were repeated every other week. Electrocardiography was repeated frequently during the first three courses and thereafter if clinically significant. A final assessment was to be made after patients went off study. Formal tumor measurements were performed at 6-week intervals until documentation of progressive disease. Standard WHO response criteria were used.

Drug Administration. The "de Gramont" regimen includes $200 \mathrm{mg} / \mathrm{m}^{2} \mathrm{LV}$ as a 2-h infusion followed by an i.v. bolus $5-\mathrm{FU}) 400 \mathrm{mg} / \mathrm{m}^{2}$ ) and a $22-\mathrm{h}$ infusion of $600 \mathrm{mg} / \mathrm{m}^{2} 5-\mathrm{FU}$ on days 1 and 2, administered every 2 weeks for a maximum of 12 cycles (16). All of the patients received premedication with 5HT3 antagonists. From cycle 2 onwards, SAM486A was administered as a $1-3-\mathrm{h}$ infusion on days $1-3$, to be given on days 1 and 2 with the i.v. bolus 5-FU and, on day 3, $3 \mathrm{~h}$ before the end of the 22-h infusion of 5-FU. SAM486A (Novartis Pharma AG,
Basel, Switzerland) was supplied as a freeze-dried, light yellow powder for reconstitution in a $5 \%$ dextrose solution. Besides the active ingredient, the formulation contained lactic acid, mannitol, and sodium chloride. The reconstituted solution was administered using a syringe infusion pump. The infusion time of 1-3 $\mathrm{h}$ was based on Phase I data demonstrating facial flushing, paresthesias, and somnolence with shorter infusion duration (9). Furthermore, Phase I data suggested a SAM486A dosing frequency of three infusions semimonthly, and a starting daily dose of $25 \mathrm{mg} / \mathrm{m}^{2}$ SAM 486 A was selected based on tolerability in Phase I trials. The starting dose was less than one-third of the single-agent maximum tolerated dose (MTD; Refs. 8, 9). For dose escalation, a modified continual reassessment method was used (17). In each cohort, at least three patients were treated and were evaluated for DLT after receiving one cycle of the combination treatment. On the basis of this updated information, the dose level for the next cohort was determined, and a maximum of $100 \%$ increase in dosage was allowed. The MTD was defined as the dose that was recommended by the modified-continualreassessment method after a minimum of 15 patients had been treated in the study and at which at least 6 patients had been enrolled. In addition, the MTD was defined as the highest daily dose of SAM486A given for 3 days in combination with a fixed-dose every 2 weeks of 5-FU and LV at which no more than $25 \%$ of the patients treated at that dose level experienced DLT. DLT was defined as grade 4 neutropenia lasting more than 5 days, neutropenic fever, any grade 4 thrombocytopenia, and any nonhematological toxicity of more than grade 2 except alopecia, inadequately treated nausea/vomiting, and/or diarrhea.

Sample Collection and Processing. Blood samples were taken in all of the patients during cycles 1 and 2. Blood volumes of 5-10 $\mathrm{ml}$ were drawn from a peripheral venous access device inserted in the arm contralateral to the drug infusion. In patients selected to receive the $125-\mathrm{mg} / \mathrm{m}^{2} /$ day dose of SAM486, samples for 5-FU analysis were collected before the bolus infusion and at 5, 10, 20, and $30 \mathrm{~min} ; 1,2,7,22$ (just before end of infusion), 22.25 (15 min after end of infusion) h, and $22.5 \mathrm{~h}$ (30 min after end of infusion) after the bolus. For determination of SAM486A concentrations, blood samples were collected immediately before the third SAM486A infusion, and just before (10 $\mathrm{min}$ ) the end of the infusion, and at 1, 3, 6, 8, 20-24, and 44-48 $\mathrm{h}$ after the end of SAM486A infusion. All of the blood samples were collected in Vacutainer tubes containing sodium heparin (Becton Dickinson, Meylan, France) and were inverted several times and immediately placed on ice. Within $15 \mathrm{~min}$ of blood collection, samples were centrifuged at room temperature for 15 min at $2500 \times g$ to yield plasma, which was stored frozen at $-20^{\circ} \mathrm{C}$ in polypropylene vials (Eppendorf, Hamburg, Germany) until analysis.

Drug Analysis. Concentrations of 5-FU in plasma were determined using a validated analytical procedure based on high-performance liquid chromatography (18). Sample pretreatment involved a solvent extraction of 1-ml aliquots with five volumes of ethyl acetate (extraction recovery, >90\%). Chromatographic separations of the analyte, the internal standard (5-chlorouracil), and matrix constituents were achieved on a 5 - $\mu \mathrm{m}$ Inertsil ODS-3 column $(250 \times 4.6 \mathrm{~mm}$ inner diameter $)$ and isocratic elution with acidified water $(\mathrm{pH} 2.0)$. The column effluent was monitored at a wavelength of $266 \mathrm{~nm}$. The lower 
Table 1 Patient characteristics

\begin{tabular}{|c|c|c|}
\hline Characteristic & & No. of patients \\
\hline Patients included & & 28 \\
\hline \multicolumn{3}{|l|}{ Sex } \\
\hline Male & & 14 \\
\hline Female & & 14 \\
\hline \multicolumn{3}{|l|}{ Age, years } \\
\hline Median & 57 & \\
\hline Range & $22-79$ & \\
\hline \multicolumn{3}{|l|}{ Performance score (ECOG) } \\
\hline 0 & & 8 \\
\hline 1 & & 20 \\
\hline \multicolumn{3}{|l|}{ Primary site of disease } \\
\hline Colon & & 19 \\
\hline Rectum & & 8 \\
\hline Pseudomyxoma peritonei & & 1 \\
\hline \multicolumn{3}{|l|}{ Prior therapy } \\
\hline Surgery & & 27 \\
\hline Radiotherapy & & 7 \\
\hline Chemotherapy & & 6 \\
\hline
\end{tabular}

${ }^{a}$ ECOG, Eastern Cooperative Oncology Group.

limit of quantitation was $0.20 \mu \mathrm{M}(\sim 26 \mathrm{ng} / \mathrm{ml})$. Concentrations of SAM486A in plasma were also determined using a liquid chromatographic assay. One-ml sample aliquots, containing the structural analog CGP 51467 as an internal standard, were analyzed. The analytes were separated from interfering plasma proteins by on-line dialysis across a Cuprophan membrane (molecular weight limit, $M_{\mathrm{r}}$ 15,000) using a Gilson ASTED XL on-line deproteinization autosampler fitted with a flat-bed dialyzer. The dialysate was loaded onto a trace-enrichment cartridge, and the concentrated analytes were eluted from the trace-enrichment cartridge into the analytical column with highperformance liquid chromatography mobile phase. Chromatographic separation of the compounds was achieved using a 3.5- $\mu \mathrm{m}$ Zorbax $\mathrm{SB}-\mathrm{C}_{8}$ column $(150 \times 4.6 \mathrm{~mm}$ inner diameter $)$ and eluted with a $0.01 \mathrm{~m}$ solution of octanesulfonate in a mixture of $0.01 \mathrm{M}$ potassium phosphate buffer $(\mathrm{pH} 2.5)$ and acetonitrile (78:22), at a flow rate of $1 \mathrm{ml} / \mathrm{min}$. The analytes were detected with a UV detector monitoring at a wavelength of $230 \mathrm{~nm}$. The lower limit of quantitation was based on the accuracy and precision of sample determinations. It was set at the lowest concentration quality-control sample for which accuracy was in the range $80-120 \%$ and precision was $\leq 20 \%$ coefficient of variation. During the course of the study, the dynamic range of the method was adjusted to the concentrations expected in the study samples. For different assay runs, therefore, the lower limit of quantitation varied from 5 to $50 \mathrm{ng} / \mathrm{ml}$.

Calibration curves $(y=m x+b)$, were generated from the plots of the peak area ratios ( $y$ ) of 5-FU and SAM486A to the internal standard versus the concentrations $(x)$ of the calibration samples, using weighted $(1 / y)$ linear least-squares regression. Concentrations in quality control and study samples were calculated using a validated macro from the resulting peak area ratios and interpolation from the regression equations of the respective calibration curves.

PK Analysis. Pharmacokinetic (PK) analysis was performed by noncompartmental analysis using WinNonlin Professional (version 1.5) software (Scientific Consulting, Inc). The $A U C_{0-\mathrm{t}}$ (area under the plasma concentration-time curve to the time of last measurable concentration) was calculated by the linear trapezoidal rule, and the systemic clearance was estimated as the total drug dose administered (in $\mathrm{mg} / \mathrm{m}^{2}$ ) divided by $A U C_{0-\mathrm{t}} . A U C_{0-\mathrm{t}}$ was used as an approximation of $A U C_{0-\infty}$ in the calculation of clearance because the rate constant of the terminal disposition phase could not be adequately determined in many cases. However, after the end of infusion, 5-FU levels decline to low levels very rapidly, and, therefore, the contribution to $A U C$ due to extrapolating from the last time point to infinity should be very small compared with $A U C_{0-\infty}$. The $C_{\max }$ (peak plasma concentration) was put on par with concentrations observed at the end of infusion, and the $T_{1 / 2}$ (half-life) was determined from the rate constant of the terminal disposition phase by a linear regression analysis. PK characteristics of 5-FU after concomitant treatment with SAM486A were compared with that after 5-FU treatment without SAM486A by calculation of the ratio of clearance values. Scatterplots of $A U C_{0-\mathrm{t}}$ versus dose, and of $C_{\max }$ versus dose, were created to evaluate the effect of dose on the systemic exposure and peak levels. The dose proportionality of relationships between $A U C$ or $C_{\max }$ and the administered dose of SAM486A was determined by a least-squares linear regression analysis.

Statistical Considerations. Parameters of all of the compounds are reported as mean values \pm SD. The difference in PK parameters between the 5-FU administration days and between patient cohorts was evaluated statistically using a two-sided parametric matched-pairs Student's $t$ test (after testing for normality). Ps (two-sided) of less than 0.05 were considered statistically significant. All of the calculations were done on the Number Cruncher Statistical Systems v5. $\times$ software package (J. L. Hintze, East Kaysville, UT, 1992).

Table 2 Treatment summary

\begin{tabular}{lccc}
\hline Cohort & $\begin{array}{c}\text { Dose SAM486A } \\
\left(\mathrm{mg} / \mathrm{m}^{2} / \text { day }\right)\end{array}$ & $\begin{array}{c}\text { No. of } \\
\text { patients }\end{array}$ & $\begin{array}{c}\text { Median no. } \\
\text { of cycles }\end{array}$ \\
\hline 1 & 25 & 3 & 12 \\
2 & 50 & 3 & 12 \\
3 & 100 & 3 & 12 \\
4 & 150 & 3 & 3 \\
5 & 125 & 16 & 6 \\
& Total & 28 & 12 \\
\hline
\end{tabular}

Table 3 Reasons for preliminary withdrawal

\begin{tabular}{ccc}
\hline Dose level & Patient number/after cycle & Reason \\
\hline $25 \mathrm{mg} / \mathrm{m}^{2}$ & $3 / 3$ & PD $^{a}$ \\
$50 \mathrm{mg} / \mathrm{m}^{2}$ & $1 / 9$ & PD \\
$150 \mathrm{mg} / \mathrm{m}^{2}$ & $2 / 2$ & Unrelated renal dysfunction \\
$125 \mathrm{mg} / \mathrm{m}^{2}$ & $1 / 3$ & Withdrew consent \\
& $3 / 3$ & Adverse event \\
& $4 / 3$ & Adverse event \\
& $5 / 3$ & PD \\
& $6 / 11$ & PD \\
& $8 / 6$ & PD \\
& $9 / 3$ & Adverse event \\
& UK1/7 & Adverse event \\
& UK3/6 & Adverse event \\
& UK4/4 & PD \\
& UK5/3 & PD \\
\hline
\end{tabular}

${ }^{a} \mathrm{PD}$, progressive disease, UK, United Kingdom. 
Table 4 Incidence rate per patient of all treatment-related neutropenia by severity grade

\begin{tabular}{lccccc}
\hline \multirow{2}{*}{$\begin{array}{c}\text { Maximum } \\
\text { severity grade }\end{array}$} & \multicolumn{5}{c}{ Dose level SAM486A $\left(\mathrm{mg} / \mathrm{m}^{2}\right)$} \\
\cline { 2 - 5 } & $25(n=3)$ & $50(n=3)$ & $100(n=3)$ & $125(n=14)$ & $150(n=3)$ \\
2 & 0 & 0 & 0 & 0 & 0 \\
3 & 0 & 0 & 0 & 0 & 0 \\
4 & 0 & $(33.3 \%)$ & $(66.7 \%)$ & 3 & 1 \\
& 0 & 0 & $(33.3 \%)$ & $(21.4 \%)$ & $(33.3 \%)$ \\
\hline
\end{tabular}

\section{RESULTS}

Twenty-eight patients were entered into this study. Patient characteristics are listed in Table 1; all of the patients were eligible. Only six patients received prior chemotherapy in an adjuvant setting (six cycles) at least more than 6 months before the detection of the metastatic disease. Two patients were not considered evaluable for toxicity, response, and PK analysis. They did not receive combination treatment with SAM486A because of cerebral infarction and rapid progression of skin metastases, respectively, after treatment with 5-FU and LV in cycle 1 . An additional patient received only limited treatment. He developed renal impairment after cycle 2, secondary to renovascular disease and also grade 3 fatigue and did not receive additional SAM486A. He was, however, included in the toxicity and response evaluation. Therefore, 26 patients were included in the analysis of response.

Toxicity and Compliance. A total of 214 cycles 5-FU/ LV, including 188 cycles of combined 5-FU/LV and SAM486A, were given. Table 2 lists the number of patients and the median number of cycles at each dose level. Twelve of the 26 patients received all 12 cycles. Seven patients went off study because of progressive disease (Table 3 ). The treatment was stopped in five patients because of adverse events. One patient withdrew his consent after cycle 3 , and one patient developed unrelated abnormal renal function. The hematological and main nonhematological adverse events are listed in Table 4 and 5, respectively. DLT at the dose level of $150 \mathrm{mg} / \mathrm{m}^{2}$ consisted of fatigue grade 3 in two of three patients resulting in a decrease in WHO performance score from 1 to 3 after cycle 2, i.e., after the addition of SAM486A to the 5-FU/LV regimen. After cycle one with only 5-FU/LV, there was no decline in condition seen in either patient. One of these two patients continued to be treated with SAM486A at a reduced dose of $100 \mathrm{mg} / \mathrm{m}^{2}$ for a total of 12 cycles and subsequently experienced only grade 1 fatigue. The other patient went off study because of an unrelated renal function disorder. A third patient in the $150-\mathrm{mg} / \mathrm{m}^{2}$ group experienced grade 1 fatigue and, although she complained of dizziness grade 2 and facial paresthesias grade 2 during the infusions with SAM486A, she received all 12 cycles. At the lower dose levels, drug-related fatigue was reported by 19 patients after cycle 2 or later, but it never exceeded grade 2 except in 1 patient at the dose level of $25 \mathrm{mg} / \mathrm{m}^{2}$ and 3 patients at $125 \mathrm{mg} / \mathrm{m}^{2}$, leading to a dose reduction of SAM486A to 100 $\mathrm{mg} / \mathrm{m}^{2}$ after four cycles and the termination of treatment after cycle 6 in one of these 3 patients. Eight patients at the other dose levels reported grade 1 dizziness and facial paresthesias. In seven $(27 \%)$ patients, somnolence grade 1 was observed. Skin toxicity, particularly hand-foot syndrome, was seen in 15 patients (58\%); however, in only one patient at the dose level of $125 \mathrm{mg} / \mathrm{m}^{2}$ did hand and foot syndrome toxicity exceed grade 2 resulting in a dose reduction of 5-FU/LV and cotreatment with pyridoxine (19). Only one patient at the dose level of $125 \mathrm{mg} / \mathrm{m}^{2}$ did have one episode of neutropenic sepsis. As in the Phase I single-agent studies, the periods of neutropenia were mostly short-lived. However, in eight patients, one or two times during the course, a delay of 1-2 weeks was necessary because of persistent neutropenia. This was independent of the dose SAM486A and most likely caused by the treatment with 5-FU/ LV. No cardiac toxicity was observed. Pronounced or total alopecia ( $\geq$ grade 2 ) was seen in 12 patients $(46 \%)$.

Table 5 Incidence rate per patient of all treatment nonhematological adverse events (severity $\geq$ grade 2 )

\begin{tabular}{|c|c|c|c|c|c|}
\hline \multirow[b]{2}{*}{ Adverse event } & \multicolumn{5}{|c|}{ Dose level SAM486A $\left(\mathrm{mg} / \mathrm{m}^{2}\right)$} \\
\hline & $25(n=3)$ & $50(n=3)$ & $100(n=3)$ & $125(n=14)$ & $150(n=3)$ \\
\hline Nausea & 0 & 1 & 2 & 9 & 3 \\
\hline Vomiting & 1 & 0 & 1 & 3 & 0 \\
\hline Constipation & 0 & 0 & 1 & 0 & 0 \\
\hline Diarrhea & 0 & 1 & 0 & 8 & 0 \\
\hline Stomatitis/mucosal inflammation & 0 & 1 & 1 & 8 & 2 \\
\hline Fatigue & 2 & 1 & 2 & 8 & 2 \\
\hline Hand-foot syndrome & 0 & 1 & 1 & 4 & 2 \\
\hline Dizziness & 0 & 0 & 0 & 0 & 2 \\
\hline Somnolence & 0 & 0 & 0 & 1 & 0 \\
\hline Paresthesia & 0 & 0 & 0 & 0 & 1 \\
\hline Flushing & 0 & 0 & 0 & 2 & 0 \\
\hline Neutropenic sepsis & 0 & 0 & 0 & 1 & 0 \\
\hline
\end{tabular}


Best tumor response was evaluated according to the Southwest Oncology Group method (20). Of 26 evaluable patients, of whom 25 had metastatic colorectal cancer, 8 (30\%) achieved a partial response ( 2 of them received earlier adjuvant chemotherapy) and $9(35 \%)$, stable disease.

Pharmacokinetics. Eight patients receiving the 125-mg/ $\mathrm{m}^{2} /$ day (MTD) dose of SAM486A had sufficient data for PK analysis. After administration of the bolus injection and constant rate infusion, 5-FU levels rose and then rapidly declined over $2 \mathrm{~h}$ to a steady state determined by infused 5-FU (500-750 $\mathrm{ng} / \mathrm{ml}$ ). The level of 5-FU again rapidly declined after the second 22-h infusion was stopped. This concentration-time profile is shown in Fig. 1. The 5-FU PK-curves with and without SAM486A are similar, suggesting that the pharmacokinetics of $5-\mathrm{FU}$ are unchanged by SAM486A. $A U C_{0-\mathrm{t}}$ and clearance of 5-FU after both courses were calculated for the eight patients and listed in Table 6. The geometric mean of the clearance ratios was 0.94 supporting the hypothesis that there is no PK interaction between 5-FU and SAM486A. The geometric mean 5-FU clearance for both treatments combined in this study was 63.2 (range, 32.6-106.4) liters $/ \mathrm{h} / \mathrm{m}^{2}$, similar to that reported previously (21).

During infusion of SAM486A, the level of SAM486A rose to a mean of $1640 \mathrm{ng} / \mathrm{ml}$ for the $125 \mathrm{mg} / \mathrm{m}^{2} /$ day dose. The decline of plasma concentrations immediately after the end of

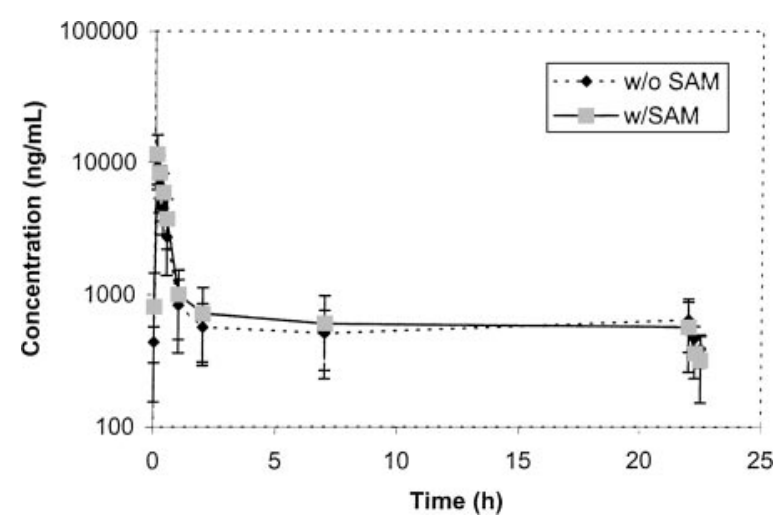

Fig. 1 Mean ( $\pm \mathrm{SD}$ ) 5-fluorouracil (5-FU) concentration-time profiles after administration of 5-FU with and without SAM486A (SAM).

Table 6 5-Fluorouracil clearance in eight patients at the dose level of $125 \mathrm{mg} / \mathrm{m}^{2}$ with and without concomitant SAM $486 \mathrm{~A}$

\begin{tabular}{rccc}
\hline & \multicolumn{2}{c}{ Clearance $\left(\right.$ liter $/ \mathrm{h} / \mathrm{m}^{2}$ ) } & \\
\cline { 2 - 3 } Patient No. & $\begin{array}{c}\text { Without } \\
\text { SAM486 }\end{array}$ & $\begin{array}{c}\text { With } \\
\text { SAM486 }\end{array}$ & $\begin{array}{c}\text { Ratio } \\
\text { (with/without) }\end{array}$ \\
\hline 13 & 37.5 & 32.6 & 0.87 \\
14 & 80.0 & 79.5 & 0.99 \\
15 & 73.5 & 75.6 & 1.03 \\
16 & 51.7 & 70.6 & 1.37 \\
17 & 69.9 & 80.3 & 1.15 \\
18 & 68.2 & 35.3 & 0.52 \\
19 & 75.8 & 47.8 & 0.63 \\
21 & 78.9 & 106.4 & 1.35 \\
Geometric mean & 65.17 & 61.30 & 0.94 \\
\hline
\end{tabular}

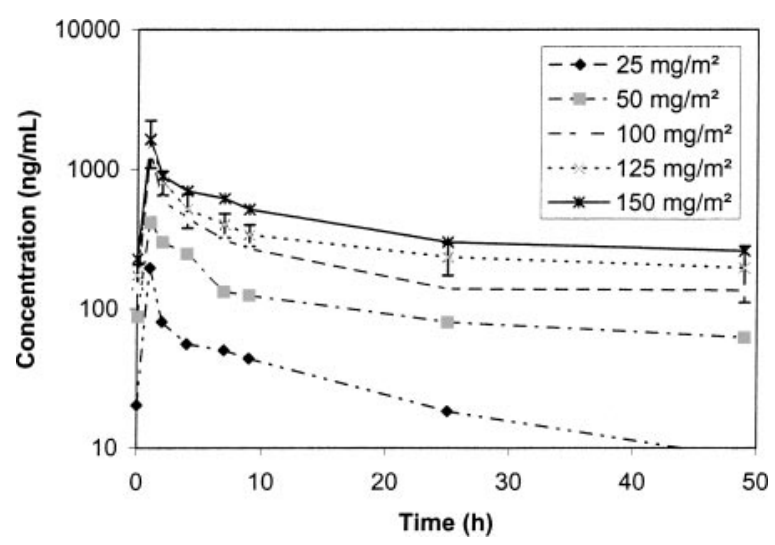

Fig. 2 Mean SAM486A concentration-time profiles after the third administration on the five different dose levels.

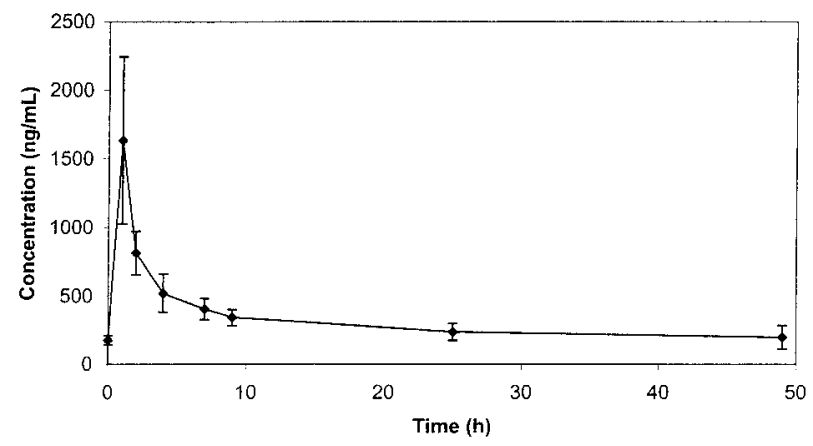

Fig. 3 Mean ( \pm SD) SAM486A concentration-time profile of 11 patients receiving $125 \mathrm{mg} / \mathrm{m}^{2} /$ day.

infusion is shown in Fig. 2, which presents a semilogarithmic plot of the mean SAM486A concentrations at each time point for the five-dose cohorts $\left(25,50,100,125\right.$, and $150 \mathrm{mg} / \mathrm{m}^{2} /$ day $)$. These data indicate that mean concentrations of SAM486A increase with an increase in the dose administered. A plot of the mean SAM486A concentration at each time point for 11 patients in the $125-\mathrm{mg} / \mathrm{m}^{2} /$ day (MTD) dose cohort is shown in Fig. 3, and the relationships between $A U C_{0-\mathrm{t}}$ and drug dose is shown in Fig. 4. The $A U C_{0-\mathrm{t}}$ was proportional to the dose of SAM486, and a linear regression analysis yielded $r^{2}$ values of 0.8 for this relationship. In patients receiving the $125-\mathrm{mg} / \mathrm{m}^{2} /$ day dose, mean values of the PK parameters were as follows: $A U C_{0-\mathrm{t}}$, $15,400 \mathrm{ng} * \mathrm{~h} / \mathrm{ml}$ (coefficient of variation, $18 \%$; number of patients, 11$) ; A U C_{0-\infty}, 27,400 \mathrm{ng} * \mathrm{~h} / \mathrm{ml}(46 \% ; n=9) ; C_{\max }, 1,640$ $\mathrm{ng} / \mathrm{ml}(37 \% ; n=11)$; and $T_{1 / 2}, 45 \mathrm{~h}(63 \% ; n=9)$. The values of $T_{1 / 2}$ and $A U C_{0-\infty}$ for two of the patients were not included in the mean, because of the uncertainty of estimating $T_{1 / 2}$ [the coefficient of determination $\left(r^{2}\right)$ for the log-linear regression of the terminal elimination phase was $<0.90]$.

\section{DISCUSSION}

The combination of novel agents with standard 5-FU/LV has been the strategy of leading clinical research programs in colorectal cancer. These include chemotherapeutic options such 


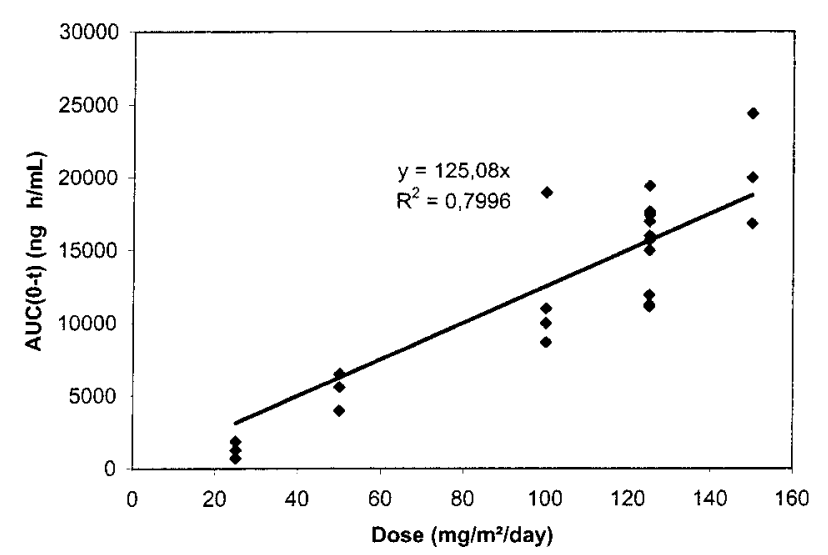

Fig. 4 SAM486A $A U C_{0-\mathrm{t}}$ (area under the plasma concentration-time curve to the time of last measurable concentration) versus dose.

as irinotecan and oxaliplatin and molecularly targeted agents such as ctuximab, Iressa, and SAM486A. In this clinical study we have demonstrated that the combination of 5-FU/LV with SAM486A is safe and has a tolerable toxicity profile.

Novel DLTs emerge when SAM486A is combined with 5-FU when compared with the single agent data for both compounds. The DLT of single-agent SAM486A was myelosuppression $(8,9,22)$; however, DLT in the present study was disabling fatigue. Although fatigue was reported in the singleagent studies, it never exceeded grade 2 , and it is not a feature of the de Gramont regimen (16). Similarly, myelosuppression in this study did not define DLT. Toxicities more pronounced than in either single-treatment program were alopecia (30\%) and hand-foot syndrome $(66 \%)$. Unchanged toxicities included paresthesias and flushing (probably related to the diluent for SAM486A) and gastrointestinal toxicities (probably related to 5-FU). Cardiovascular toxicity, including arrhythmias and myocardial ischemia seen with weekly SAM486A (9), was not seen in the present study. This change in the spectrum of toxicity suggests an interaction at the cellular but not, as we have determined, at a PK level.

In the Phase I studies with single-agent SAM486A, the pharmacokinetics of SAM486A were linear, indicating that the processes of distribution and elimination were not saturated, inhibited, nor induced. We found no PK interaction between 5-FU and SAM486A. In all of the patients, except for one, all of the treatment cycles consisted of full-dose 5-FU/LV. It was not possible to design this study to determine the effect of 5-FU treatment on SAM486A pharmacokinetics using each patient as his/her own control in a cross-over fashion. This was because of ethical considerations concerning treatment of this patient population with SAM486A alone; therefore, observations about the SAM486A pharmacokinetics are drawn from historical data. In addition, the SAM486A dosing schedule used in this study differed from that of single-agent studies to fit conveniently with the de Gramont regimen. The SAM486A schedule was shortened from 5 days of daily infusions every 3 weeks to 3 days of daily infusions every 2 weeks. The dose intensity for SAM486A of $187.50 \mathrm{mg} / \mathrm{m}^{2} /$ week at the dose recommended by this study also differed from that of the single-agent studies [weekly $180 \mathrm{mg} / \mathrm{m}^{2} /$ week and every four weeks doses at 100 $\mathrm{mg} / \mathrm{m}^{2} /$ week $\left.(8,9)\right]$. These factors make a rigorous comparison among the three SAM486A schedules difficult; nevertheless, the general features of the SAM486A concentration-time profile after i.v. infusion in this study are comparable with those of the study using the 4-week weekly treatment schedule. Mean $A U C_{0-\infty}$ and $C_{\max }$ values from the 5-day schedule were 39,200 $\mathrm{ng} * \mathrm{~h} / \mathrm{ml}$ and 2,470 $\mathrm{ng} / \mathrm{ml}$, respectively, for the MTD 102.4-mg/ $\mathrm{m}^{2} /$ day dose (22). Adjusting for the difference in dose (125 versus $102.4 \mathrm{mg} / \mathrm{m}^{2} /$ day) and for 3 days of dosing rather than 5 days, these values become $28,700 \mathrm{ng} * \mathrm{~h} / \mathrm{ml}$ and $1,810 \mathrm{ng} / \mathrm{ml}$, respectively. These estimates are similar to the values of 27,400 $\mathrm{ng} * \mathrm{~h} / \mathrm{ml}$ and $1,640 \mathrm{ng} / \mathrm{ml}$ obtained in this study. The combination treatment of 5-FU/LV using the de Gramont regimen with SAM486A is, therefore, feasible and maintains the maximum dose intensity of both agents.

The response data compare favorably with the data of de Gramont using single agent 5-FU (16). This Phase I study was not designed to determine a response rate for the combination therapy, but the data do suggest that this question should be evaluated in a Phase III study. The recommended dose of SAM486A for this study will be $125 \mathrm{mg} / \mathrm{m}^{2} /$ daily on days $1-3$ every 2 weeks.

\section{REFERENCES}

1. Pegg AE. Polyamine metabolism and its importance in neoplastic growth and as a target for chemotherapy. Cancer Res 1988;48:759-74. 2. Regenass U, Caravatti G, Mett H, et al. New $S$-adenosylmethionine decarboxylase inhibitors with potent antitumor activity. Cancer Res 1992;52:4712-8.

3. Regenass U, Mett H, Stanek J, Mueller M, Kramer D, Porter CW. CGP 48664, a new $S$-adenosylmethionine decarboxylase inhibitor with broad spectrum antiproliferative and antitumor activity. Cancer Res 1994;54:3210-7.

4. Manni A, Badger B, Wechter R, Kunselman S, Rossini A, Demers L. Biochemical and growth-modulatory effects of the new $S$-adenosylmethionine decarboxylase inhibitor CGP 48664 in malignant and immortalized human breast epithelial cells in culture. Int J Cancer 1995;62: 485-91.

5. Gutman M, Beltran PJ, Fan D, et al. Treatment of nude mice with 4-amidinoindan-1-one-2'-amidinohydrazone, a new $S$-adenosylmethionine decarboxylase inhibitor, delays growth and inhibits metastases of human melanoma cells. Melanoma Res 1995;5:147-54.

6. Thomas T, Faaland CA, Adhikarakunnathu S, Thomas TJ. Structureactivity relations of $S$-adenosyldecarboxylase inhibitors on the growth of MCF-7 breast cancer cells. Breast Cancer Res Treat 1996;39:293-306.

7. Delworth MG, Nishioka K, Pettaway C, et al. Systemic administration of 4-amidinoindanon-1-(2'-amidino)/hydrazone, a new inhibitor of $S$-adenosyl methionine decarboxylase, produces cytostasis of human prostate cancer in athymic nude mice. Int J Oncology 1997;6:293-9.

8. Paridaens R, Uges DR, Barbet N, et al. A Phase I study of a new polyamine biosynthesis inhibitor, SAM486A, in cancer patients with solid tumours. Br J Cancer 2000;83:594-601.

9. Eskens FALM, Greim GA, Van Zuylen C, et al. Phase I and pharmacologic study of weekly administration of the polyamine synthesis inhibitor SAM486A (CGP 48 664) in patients with solid tumors. Clin Cancer Res 2000;6:1736-43.

10. Machover D. A comprehensive review of 5-fluorouracil and leucovorin in patients with metastatic colorectal carcinoma. Cancer (Phila.) 1997;80:1179-87.

11. Saltz LB, Cox JV, Blanke C, et al. Irinotecan plus fluorouracil and leucovorin for metastatic colorectal cancer. N Engl J Med 2000;343: 905-14. 
12. Douillard JY, Cunningham D, Roth AD, et al. Irinotecan combined with fluorouracil compared with fluorouracil alone as first-line treatment for metastatic colorectal cancer: a multicentre randomised trial. Lancet 2000;355:1041-7.

13. de Gramont A, Figer A, Seymour M, et al. Leucovorin and fluorouracil with or without oxaliplatin as first-line treatment in advanced colorectal cancer. J Clin Oncol 2000;16:2938-47.

14. Giacchetti S, Perpoint B, Zidani R, et al. Phase III multicenter randomized trial of oxaliplatin added to chronomodulated fluorouracilleucovorin as first-line treatment of metastatic colorectal cancer. J Clin Oncol 2000;18:136-47.

15. Wallace HM, Caslake R. Polyamines and colon cancer. Eur J Gastroenterol Hepatol 2001;13:1033-9.

16. de Gramont A, Bosset JF, Milan C, et al. Randomized trial comparing monthly low-dose leucovorin and fluorouracil bolus with bimonthly high-dose leucovorin and fluorouracil bolus plus continuous infusion for advanced colorectal cancer: a French Intergroup study. J Clin Oncol 1997;2:808-15.

17. Goodman S, Zahurak M, Piantadosi S. Some practical improvements in the continual reassessment method for Phase I studies. Stat Med 1995;14:1149-61.
18. Schaaf LJ, Ferry DG, Hung CT, Perrier DG, Edwards IR. Analysis of 5'-deoxy-5-fluorouridine and 5-fluorouracil in human plasma and urine by high-performance liquid chromatography. J Chromatogr 1985; 342:303-13.

19. Fabian CJ, Molina R, Slavik M, Dahlberg S, Giri S, Stephens R. Pyridoxine therapy for palmar-plantar erythrodysesthesia associated with continuous 5-fluorouracil infusion. Investig New Drugs 1990;8: 57-63.

20. Green S, Weiss GR. Southwest Oncology Group standard response criteria, endpoint definitions and toxicity criteria. Investig New Drugs 1992;10:239-53.

21. Wattanatorn W, Mc Leod HL, Macklon F, Cassidy J, Kendle KE, Reid M. Comparison of 5-fluorouracil pharmacokinetics in whole blood, plasma, and red blood cells in patients with colorectal cancer. Pharmacotherapy 1997;17:881-6.

22. Siu LL, Rowinsky EK, Hammond L, et al. A Phase I and pharmacokinetic (PK) study of SAM486A, a novel polyamine biosynthesis inhibitor, administered on a daily-times-five every-threeweek schedule in patients with solid malignancies. Clin Cancer Res 2002;8:2157-66. 